University of Louisville

ThinkIR: The University of Louisville's Institutional Repository

$12-2014$

\title{
The impact of mindfulness and test anxiety on academic performance.
}

Mariam A. Altairi

University of Louisville

Follow this and additional works at: https://ir.library.louisville.edu/honors

Part of the Cognition and Perception Commons, and the Cognitive Psychology Commons

\section{Recommended Citation}

Altairi, Mariam A., "The impact of mindfulness and test anxiety on academic performance." (2014).

College of Arts \& Sciences Senior Honors Theses. Paper 39.

http://doi.org/10.18297/honors/39

This Senior Honors Thesis is brought to you for free and open access by the College of Arts \& Sciences at ThinkIR: The University of Louisville's Institutional Repository. It has been accepted for inclusion in College of Arts \& Sciences Senior Honors Theses by an authorized administrator of ThinkIR: The University of Louisville's Institutional Repository. This title appears here courtesy of the author, who has retained all other copyrights. For more information, please contact thinkir@louisville.edu. 
The Impact of Mindfulness and Test Anxiety on Academic Performance

By

Mariam A. Altairi

Submitted in partial fulfillment of the requirements

for Graduation summa cum laude

and

for Graduation with Honors from the Department of Psychology

University of Louisville

December, 2014 
The Impact of Mindfulness and Test Anxiety on Academic Performance

In everyday life, anxiety can have negative effects on an individual's experience and state of mind. In the classroom, this could translate into detrimental effects on students' experience and overall academic record. Poor performance and a disinterest in learning are common in students with anxiety disorder, and the effects only worsen as the course difficulty increases (Vitasari, Wahab, Othman, Herawan, \& Sinnadurai, 2010). For this reason, researchers have examined the aforementioned relationship in hopes of ameliorating student academic performance in the face of test anxiety.

One personality characteristic associated with a reduced impact of anxiety is mindfulness. Trait mindfulness can be defined as the characteristic of being fully attentive to the present experience without judgment or emotional distraction (Jha, Stanley, Kiyonaga, Wong, \& Gelfand, 2010). Individuals exhibiting high levels of this trait acknowledge anxious thoughts, but do not pass judgment nor ruminate on them. Thus, individuals with higher trait mindfulness still experience anxious thoughts, they are merely less impacted by them. The current study investigates whether this positive effect of trait mindfulness is associated with a reduced impact of test anxiety on academic performance in an undergraduate engineering course.

\section{Cognitive Test Anxiety and Academic Performance}

Although the incorporation of mindfulness in studies involving the academic setting is fairly new, research on other factors impacting student work has been under investigation for some time. One predominant area of research is test anxiety, the physiological and behavioral reactions associated with worry regarding negative consequences or poor performance on an exam (Zeidner, 1998). As the emphasis on academic and standardized testing has increased, researchers have investigated the impact of test anxiety on exam performance (Cassady \& 
Johnson, 2002). Anxiety can stem from many course-related issues, including inadequate preparation, comparing performance to peers, disappointing parents, consequences of performing poorly, and more (Cassady \& Johnson, 2002; Culler \& Holohan, 1980).

Ultimately, the anxiety that comes from situations related to coursework can have a detrimental effect on memory span, concentration, confidence, and reasoning (Vitasari et al., 2010). Generally, much research has acknowledged that test anxiety disrupts working memory (WM) (Eysenck, 2012), which is the cognitive system consisting of executive attention during performance. Essentially, it uses attention to focus on relevant information and inhibit irrelevant information that comes from distracting or interfering thoughts (Engle, 2002). WM is important for a wide range of higher-order cognitive tasks such as problem solving, reasoning, and reading comprehension (Beilock, 2008; Engle 2002).

Studies examining math anxiety in particular converge with these findings. For instance, Ashcraft (2002) noted that student math anxiety could lead to lower scores in both math achievement and competence when problems rely heavily on WM resources (e.g., problems involving long division and carrying). Math anxiety is thought to lead to performance-related worries and ruminations that compete for the WM resources necessary to complete the problems (Ashcraft, 2002; Beilock, 2008). Cognitive processing is hampered by math anxiety as a result of WM resources shifting from solving math to anxious thoughts (Ashcraft 2002). Therefore, students with higher math anxiety score more poorly than their actual ability, because WM is coopted in the anxiety-provoking situation.

A related body of research has demonstrated that high-pressure testing situations generally increased worrying and negative thinking in participants, which reduced performance on WM-demanding math problems (DeCaro, Rotar, Kendra, \& Beilock, 2010). Other research 
has demonstrated that even mild symptoms of anxiety on visual and auditory tasks can lead to poor working memory performance, poor concentration on said tasks, and possibly poor academic performance (Aronen, Vuontela, Steenari, Salmi, \& Carlson, 2005).

The impact of anxiety on academic performance may have particular significance for students in especially difficult courses. Vitasari et al. (2010) found a relationship between high anxiety and low academic performance in engineering students, as evidenced by self-reported anxiety levels and score reports on official examinations. These effects on performance could also have lasting impressions on students' overall academic record. Chapell et al. (2005) measured students' self-reported anxiety levels before, during, and after the testing process. Results indicated that there was a significant inverse relationship between test anxiety and overall undergraduate and graduate GPA. Similarly, engineering students scoring higher on anxiety measures had lower GPAs in the study performed by Vitasari et al. (2010).

\section{Mindfulness}

Due to its significance in treating both physical and psychological afflictions, research on mindfulness has grown exponentially since 1996 (Black, 2014). The absence of emotional distraction during mindfulness (Jha et al., 2010) allows thought processes to be uninhibited by emotion. In doing so, individuals are able to discern negative feelings, such as anxiety (Bishop et al., 2004), and become less susceptible to its impact. This ability to identify and label anxiety could potentially help individuals mitigate its effects on performance.

Although early research focused primarily on the effects of mindfulness on populations suffering from chronic pain and illness (Anderson, Lau, Segal, \& Bishop, 2007), contemporary studies have shifted their focus to the benefits of mindfulness training on cognition. For example, Chambers, Lo, and Allen (2008) studied the impact of intensive mindfulness meditation on 
various performance tasks, and found that people who participated in mindfulness training had enhanced sustained attention and working memory capacity.

Consistent with this idea, Mrazek, Franklin, Phillips, Baird, and Schooler (2013) examined the effects of mindfulness training on mind wandering and performance on the Graduate Record Examination (GRE). Scores on standardized tests such as the GRE are thought to represent a student's ability to succeed in higher education. These researchers found that reading comprehension scores were improved after mindfulness training, and the reduction of distracting thoughts mediated this effect. These findings support the notion that mindfulness includes the processes of regulating, sustaining, and switching attention while inhibiting elaborative processing (Bishop et al., 2004).

Furthermore, mindfulness could improve academic performance through enhanced emotional awareness. Researchers assert that mindfulness "would likely result in greater capacity to distinguish feelings from bodily sensations unrelated to emotional arousal" (Bishop et al., 2004, p. 234). By discerning between task-related thoughts and distracting emotional responses, it could be argued that mindfulness would prevent the physiological effects of anxiety from impeding thoughts during academic performance.

\section{Mindfulness, Cognitive Test Anxiety, and Academic Performance}

Several researchers have attributed higher levels of trait mindfulness to decreases in stress and anxiety as well as improvements in attention and mood (Anderson et al., 2007; Brown \& Ryan, 2003; Chiesa \& Serretti, 2009; Tang et al., 2007). In addition, mindfulness training has been demonstrated to lessen the negative effects of anxiety on physical and psychological health, significantly reducing anxiety and depression (Reibel, Greeson, Brainard, \& Rosenzweig, 2001). 
Therefore, one important question is whether the benefits of mindfulness on academic performance can be explained by reductions in test anxiety.

Increased mindfulness could prevent the reallocation of WM resources to anxious thoughts, and enable attention to be shifted from task-related stressors to task-related information needed to complete the activity at hand. Mrazek et al. (2013) demonstrated that mind wandering, or switching the focus of attention to non-task-related concerns such as environmental stressors, could impede academic performance. In addition, because mindfulness improves both WMC and cognitive control (Brown \& Ryan, 2003; Jha et al., 2010), and higher WMC is associated with better performance on cognitively demanding tasks (Engle, 2002), mindfulness may also help to reduce test anxiety in students. Therefore lower levels of academic anxiety, particularly test anxiety, could potentially improve performance overall. Specifically, the more capacity for working memory to function, the less need there is for cognitive processes associated with performance to compete for working memory (Beilock, 2008).

\section{Current Study}

As reviewed above, studies have separately determined that mindfulness is associated with reduced anxiety, and that mindfulness is associated with improved performance on WMdemanding academic tasks. The current study examined whether the cognitive benefits of mindfulness might be explained by a reduced susceptibility to anxiety. To my knowledge, there is no direct evidence suggesting a relationship between mindfulness, test anxiety, and academic performance. For the current study, the primary research question was: can the benefits of trait mindfulness on academic performance be explained by reductions in trait cognitive test anxiety? With this in mind, I investigate whether trait cognitive test anxiety mediates the effect of trait mindfulness on academic performance in undergraduate students. 
Based on the literature reviewed above, I predicted that (1) higher trait mindfulness would be associated with better course performance and with lower trait cognitive test anxiety, (2) that higher trait cognitive test anxiety would be associated with poorer course performance, and (3) that trait cognitive test anxiety would mediate the relationship between trait mindfulness and course performance. Thus, students who report greater trait mindfulness should experience lower levels of trait cognitive test anxiety, which would enable them to score higher on the course examinations.

By examining the relationships between these three variables, researchers would be better equipped to examine potential individual differences in predicting course performance in engineering courses as well as other disciplines. Ultimately, the results of this study can inform future interventions to improve student performance by combatting trait cognitive test anxiety with techniques that promote mindfulness. These results would also inform the literature on mindfulness and test anxiety, by showing the link between these two variables, and how they relate to course performance.

\section{Method}

\section{Participants}

Participants $(N=250)$ were full-time, freshmen students at the University of Louisville who were enrolled in an introductory engineering calculus course during the Fall 2013 semester. The sample included 61 female (24\%) and 189 male (76\%) students, of whom 225 were Caucasian (90.0\%), 4 were Black (1.6\%), 7 were Asian (2.8\%), 4 were Hispanic or Latino (1.6\%), 5 were two or more races (2.0\%), and 5 had unknown ethnicities (2.0\%). Participants had Fall 2013 GPAs ranging from 0.69 to $4.00(M=3.16, S D=0.63)$, which included performance in the engineering course in question. Participants also had ACT math scores 
ranging from 25 to $36(M=30.6, S D=2.5)$, and Algebra Readiness Examination scores ranging from $23 \%$ to $100 \%(M=74.9 \%, S D=17.0 \%)$.

\section{Questionnaires}

The questionnaires used in the current study were given as part of a larger study. Of four questionnaires administered, only two are relevant to the current study: the Cognitive Test Anxiety Scale and the Mindfulness Attention Awareness Scale. Both questionnaires have been used in previous research examining test anxiety or mindfulness in students (e.g., Cassady \& Johnson, 2002; Chambers et al., 2008; Chiesa \& Serretti, 2009). The Cognitive Test Anxiety Scale included 27 questions such as "I lose sleep over worrying about examinations," and "When I take a test, my nervousness causes me to make careless errors." Participants rated each item on a scale of 1 ("not at all typical of me") to 4 ("very typical of me") (Cassady, 2004) and their final score represented the sum of each rating. Cassady (2004) found Cronbach's alpha to be 0.93, whereas the current study demonstrates a lower internal consistency $(\alpha=0.68)$.

The Mindfulness Attention Awareness Scale (MAAS) measured differences in trait mindfulness by using 15 items such as "I find it difficult to stay focused on what's happening in the present," and "I do jobs or tasks automatically, without being aware of what I'm doing" (Brown \& Ryan, 2003). Participants rated each item on a scale of 1 ("almost always") to 6 ("almost never") and their final score was the sum total of each rating. In previous research, Cronbach's alpha was found to be 0.81 (Brown \& Ryan, 2003). In the current study, Cronbach's alpha was 0.87 .

\section{Academic Performance}

Participants' Engineering 101 performance was measured by their grades throughout the course, including homework, quizzes, exams, and a final exam. Specifically, participants 
completed fifteen homework assignments (accounting for $5 \%$ of their overall grade), twelve quizzes (accounting for $15 \%$ of their overall grade), fourteen exams (accounting for $50 \%$ of their overall grade), and one final exam (accounting for $25 \%$ of their overall grade). Of these grades, our dependent measure was the average score on the fifteen exams, which represent three-fourths of the participants' final course grade.

\section{Procedure}

Students completed all course assignments and assessments as outlined in the course syllabus. Eight weeks into the semester, all students received an email requesting that they complete a set of online questionnaires as part of a research study. These questionnaires were selected to assess factors related to performance and retention in a first-year engineering calculus course. After providing informed consent, participants had approximately thirty minutes of class time to complete the questionnaires detailed above on their personal computers while their professor remained in the classroom. A debriefing page was made viewable for the participants after finishing the questionnaires. Upon completion of the course, grades were connected to survey responses by a third party (Institutional Research) and all identifying information was removed from the data.

\section{Results}

Data from the surveys and course performance were analyzed in order to determine if mindfulness and test anxiety predicted course performance, as well as whether the expected positive relationship between mindfulness and academic performance was mediated by test anxiety. Multiple linear regressions were used to predict a continuous dependent variable (i.e., course performance) from multiple independent variables (i.e., trait mindfulness, trait cognitive test anxiety). In order to test the mediation hypothesis, I adopted Baron and Kenny's (1986) four- 
step process using a series of multiple linear regression models to show that (1) trait mindfulness was associated with exam performance, (2) trait mindfulness was associated with trait cognitive test anxiety, (3) trait cognitive test anxiety remained associated with exam performance even after controlling for trait mindfulness, and (4) trait mindfulness no longer significantly affected course performance when accounting for trait cognitive test anxiety. All analyses were performed while controlling for participants' gender and math ability (i.e. ACT math scores and Algebra Readiness Exam scores). Overall, multiple linear regression was the most appropriate analysis for the type of variables being analyzed, the overarching goal of the research project, and identifying mediating variables.

First, researchers examined whether trait mindfulness was associated with exam performance. The linear regression analysis revealed that mindfulness was a significant predictor of exam performance ( $\beta=0.001, p=0.019)$, accounting for $28 \%$ of the variance in exam performance $\left(R^{2}=0.28\right)$. Trait mindfulness had a significant effect on cognitive test anxiety $(\beta=$ $-0.052, p<0.001)$ and explained a significant proportion of variance in cognitive test anxiety $\left(R^{2}\right.$ $=0.28)$.

Next, exam performance was regressed on trait cognitive test anxiety with an added control of trait mindfulness. Trait cognitive test anxiety significantly predicted exam performance $(\beta=-0.001, p=0.013)$. While accounting for trait cognitive test anxiety however, trait mindfulness no longer significantly affected course performance $(\beta=0.001, p=0.262)$. This result is consistent with the idea that trait cognitive test anxiety mediates the relationship between trait mindfulness and course performance. In other words, students who report greater trait mindfulness should experience lower levels of trait cognitive test anxiety, which will enable them to score higher on the course exams. This would indicate that trait mindfulness has an 
indirect effect on course performance, which is fully mediated by a direct effect of trait cognitive test anxiety.

\section{Discussion}

The objective of this study was to investigate whether trait cognitive test anxiety could mediate the effect of trait mindfulness on the academic performance of first-year undergraduate students in an engineering calculus course. In turn, this would suggest that trait mindfulness could ameliorate academic performance by reducing trait cognitive test anxiety. By collecting exam scores as well as scores on both the Cognitive Test Anxiety Scale (CTAS) and the Mindfulness Attention Awareness Scale (MAAS), I was able to construct linear regression models to determine the existence of an overarching relationship between trait mindfulness, trait cognitive test anxiety, and exam performance.

The present study provides additional evidence for multiple relationships discussed in previous research. First, the data revealed a positive relationship between trait mindfulness and course performance (Chambers et al., 2008; Mrazek et al., 2013). Second, there was a negative relationship between trait mindfulness and trait cognitive test anxiety (Anderson et al., 2007; Brown \& Ryan, 2003; Chiesa \& Serretti, 2009; Tang et al., 2007). Third, there was a negative relationship between trait cognitive test anxiety and course performance (Ashcraft 2002; Beilock, 2008).

The unique contribution to the literature was that, although students' trait mindfulness was a significant predictor of their course performance, trait mindfulness only had an indirect effect on course performance. The relationship between trait mindfulness and course performance was mediated by trait cognitive test anxiety. The direct effect of anxiety on academic performance has been demonstrated with engineering students, but without the 
consideration of trait mindfulness (Vitasari et al., 2010). Importantly, the current study asserts that students who had higher levels of trait mindfulness also experienced lower levels of trait cognitive test anxiety, and ultimately performed better on the course exams. These findings help connect several findings in the literature that separately link mindfulness to reduced anxiety (e.g., Anderson et al., 2007; Brown \& Ryan, 2003; Chiesa \& Serretti, 2009; Tang et al., 2007) and test anxiety to reduced course performance (e.g., Ashcraft, 2002; Cassady \& Johnson, 2002; Culler \& Holohan, 1980; Vitasari et al., 2010).

One limitation of this study is that the variables were not manipulated in an experimental setting. Therefore, causality cannot be inferred. However it is worth noting that in this study, Cronbach's alpha for both the CTAS and MAAS questionnaires were relatively high. Since the internal consistencies measured as such, the concern for measurement error due to self-report is minimized. Future research could examine the impact of a mindfulness intervention on both cognitive test anxiety and academic performance. Future research might also experimentally manipulate feelings of anxiety, such as by inducing a high-pressure situation in the laboratory (e.g., Beilock, 2008; DeCaro et al., 2010). The impact of trait mindfulness on state anxiety, and subsequent performance under pressure, could be examined.

Ultimately, this line of work helps clarify how individual differences in cognitive test anxiety and mindfulness can help predict course performance, which can be used when designing interventions that target students who are most likely to struggle and drop out. Finally, some authors have argued that specialized programs to enhance performance on standardized tests should incorporate techniques commonly found in mindfulness training, such as relaxation and stress management (Schachter, 2007). While this notion is noble, additional research is 
warranted to determine the most impactful mechanisms, which should be the basis for large-scale interventions designed to enhance academic performance. 


\section{References}

Anderson, N. D., Lau, M. A., Segal, Z. V., \& Bishop, S. R. (2007). Mindfulness based stress reduction and attentional control. Clinical Psychology \& Psychotherapy, 14(6), 449-463.

Aronen, E. T., Vuontela, V. V., Steenari, M. R., Salmi, J. J., \& Carlson, S. S. (2005). Working memory, psychiatric symptoms, and academic performance at school. Neurobiology Of Learning \& Memory, 83(1), 33-42. doi:10.1016/j.nlm.2004.06.010

Ashcraft, M. H. (2002). Math anxiety: Personal, educational, and cognitive consequences. Current Directions in Psychological Science, 11(5), 181-185.

Baron, R. M., \& Kenny, D. A. (1986). The moderator-mediator variable distinction in social psychological research: Conceptual, strategic, and statistical considerations. Journal of personality and social psychology, 51(6), 1173.

Beilock, S. L. (2008). Math Performance in Stressful Situations. Current Directions In Psychological Science (Wiley-Blackwell), 17(5), 339-343. doi:10.1111/j.14678721.2008.00602.x

Bishop, S.R., Lau, M., Shapiro, S., Carlson, L., Anderson, N.D., Carmody, J., Segal, Z.V., Abbey, S., Speca, M., Velting, D., \& Devins, G. (2004). Mindfulness: A proposed operational definition. Clinical Psychology: Science and Practice, 11(3), 230-241.

Black, D. S. (2014). Mindfulness-based interventions: An antidote to suffering in the context of substance use, misuse, and addiction. Substance Use \& Misuse, 49(5), 487-491. doi: $10.3109 / 10826084.2014 .860749$

Brown, K. W., \& Ryan, R. M. (2003). The benefits of being present: mindfulness and its role in psychological well-being. Journal of personality and social psychology, 84(4), 822. 
Cassady, J. C. (2004). The influence of cognitive test anxiety across the learning-testing cycle. Learning and Instruction, 14, 569-592.

Cassady, J. C., \& Johnson, R. E. (2002). Cognitive test anxiety and academic performance. Contemporary Educational Psychology, 27(2), 270. doi:10.1006/ceps.2001.1094

Chambers, R., Lo, B. C. Y., \& Allen, N. B. (2008). The impact of intensive mindfulness training on attentional control, cognitive style, and affect. Cognitive Therapy and Research, 32(3), 303-322. doi:10.1007/s10608-007-9119-0

Chapell, M. S., Blanding, Z., Takahashi, M., Silverstein, M. E., Newman, B., Gubi, A., \& McCann, N. (2005). Test anxiety and academic performance in undergraduate and graduate students. Journal of educational psychology, 97(2), 268-274. doi:10.1037/00220663.97.2.268

Chiesa, A., \& Serretti, A. (2009). Mindfulness-based stress reduction for stress management in healthy people: A review and meta-analysis. The journal of alternative and complementary medicine, 15(5), 593-600.

Culler, R. E., \& Holohan, C. J. (1980). Test anxiety and academic performance: The effects of study-related behaviors. Journal of Educational Psychology, 72, 16-26.

DeCaro, M. S., Rotar, K. E., Kendra, M. S., \& Beilock, S. L. (2010). Diagnosing and alleviating the impact of performance pressure on mathematical problem solving. Quarterly Journal of Experimental Psychology, 63(8), 1619-1630. doi:10.1080/17470210903474286

Engle, R. W. (2002). Working memory capacity as executive attention. Current Directions in Psychological Science, 11(1), 19-23. 
Eysenck, M. W. (2012). The impact of anxiety on academic performance. In Kreitler, S. (Ed.), Cognition and motivation: Forging an interdisciplinary perspective (pp. 96-108). New York, NY: Cambridge University Press.

Jha, A. P., Stanley, E. A., Kiyonaga, A., Wong, L., \& Gelfand, L. (2010). Examining the protective effects of mindfulness training on working memory capacity and affective experience. Emotion, 10(1), 54-64.

Mrazek, M. D., Franklin, M. S., Phillips, D., Baird, B., \& Schooler, J. W. (2013). Mindfulness training improves working memory capacity and GRE performance while reducing mind wandering. Psychological Science, 24(5), 776-781. doi:10.1177/0956797612459659

Reibel, D. K., Greeson, J. M., Brainard, G. C., \& Rosenzweig, S. (2001). Mindfulness-based stress reduction and health-related quality of life in a heterogeneous patient population. General Hospital Psychiatry, 23(4), 183-192.

Schachter, R. (2007). Enhancing performance on the scholastic aptitude test for test-anxious high school students. Biofeedback, 35, 105-109.

Tang, Y. Y., Ma, Y., Wang, J., Fan, Y., Feng, S., Lu, Q., Yu, Q., Sui, D., Rothbart, M. K., Fan, M., \& Posner, M. I. (2007). Short-term meditation training improves attention and selfregulation. Proceedings of the National Academy of Sciences, 104(43), 17152-17156.

Vitasari, P., Wahab, M., Othman, A., Herawan, T., Sinnadurai, S. (2010). The relationship between study anxiety and academic performance among engineering students. ProcediaSocial and Behavioral Sciences, 8, 490-497.

Zeidner, M. (1998). Test anxiety: The state of the art. New York: Plenum Press. 